\title{
A QUANTITATIVE ASSESSMENT OF MUSCLE SPINDLE FORMATION IN REINNERVATED AND NON-REINNERVATED GRAFTS OF THE RAT EXTENSOR DIGITORUM LONGUS MUSCLE
}

\author{
Sherry L. Rogers and B. M. CARLSON \\ Departments of Anatomy and Biological Sciences, University of Michigan, Ann Arbor. \\ Michigan 48109. U.S.A.
}

\begin{abstract}
Free grafting of the rat extensor digitorum longus muscle disrupts the neurovascular supply and results in degeneration and subsequent regeneration of both muscle and nerve. Reinnervation of one group of grafts was prevented by severing and ligating the sciatic nerve. Thirty days after surgery, the number of muscle spindles in each graft was determined by examination of serial sections at the light-microscopic level. Non-operated control muscles contained $37.86 \pm 3.02$ (S.D.) spindles per muscle. Means for the reinnervated and non-reinnervated grafts were $15.63 \pm 3.89$ and $18.38 \pm 5.15$ respectively. At the time of surgery, all of these grafts had been treated with $0.75 \%$ bupivacaine, a local anesthetic which, combined with the grafting technique, ensures degeneration of all muscle fibers. An additional group of grafts was not subjected to this treatment and contained a mean of $27.40 \pm 2.19$ spindles.

The embryogenesis of muscle spindles is dependent upon interaction between sensory nerves and developing myotubes. The conditions for the formation of these stretch receptors in regenerating muscle have been less clear. Their formation in non-reinnervated grafts demonstrates that this process, unlike spindle development in the embryo, does not require the presence of nerves. When reinnervation of a graft is allowed, large numbers of nerve fibers have been observed in muscle spindles. It is not yet known whether or not the normal pattern of innervation, essential for proper function of the spindle, is restored.
\end{abstract}

MUSCLE spindles have been observed in free grafts of entire muscles of the rat (CARLSON \& GUTMANN, 1975; Schmalbruch, 1976) and cat (Hakelius, NysTRÖM \& STÅLBERG, 1975), but not in regenerated minced muscle (Carlson, 1973; Zelená \& SobotKOVA, 1971; ZHENEVSKAYA, 1974). In both experimental systems, neuromuscular contacts are disrupted by the operation, and degeneration and subsequent regeneration of both nerve and muscle occur. It is not known whether the spindles which are observed in the free grafts regain their normal morphological and functional characteristics. The specific requirements for the formation of these sensory receptors in regenerating muscle are also not known.

In normal muscle, specific patterns of innervation, both sensory and motor, are critical to the proper functioning of the spindle. These neuromuscular relationships are established early in development, with the differentiation of the spindle being particularly dependent upon contact between sensory nerves and developing muscle fibers (Milburn, 1973; Zelená, 1957; Zelená \& Hník, 1960; Zelená \& Soukup, 1973). In the rat, muscles deprived of sensory innervation during a critical period of development do not acquire normal numbers of spindles. These observations raise several questions regarding the formation of spindles in regenerating muscle. Does this process resemble the embryological development of these

Abbreviation: EDL, extensor digitorum longus. structures? Specifically, is any neural dependency involved? When conditions allow their regeneration, does a muscle regain its full complement of spindles? This study examines these questions by quantitative analysis of spindle formation in both reinnervated and non-reinnervated free grafts of the rat extensor digitorum longus (EDL) muscle.

\section{EXPERIMENTAL PROCEDURES}

\section{Control animals}

Under ether anesthesia, 7 EDL (extensor digitorum longus) muscles were removed from male Sprague-Dawley rats weighing between 336 and $462 \mathrm{~g}$. The sample included muscles from both right and left legs.

\section{Experimental animals}

All animals were anesthetized with ether for surgery and autopsy. Free grafting of EDL muscles in male SpragueDawley rats weighing between 180 and $240 \mathrm{~g}$ was performed following the technique of CARLSON \& GUTMANN (1975) Muscles were removed from the limb by severing their tendons of origin and insertion and their neurovascular supply. After replacement in their original beds. the muscles were sutured to their tendons and covered by overlying fascia and skin. This procedure initjally results in ischemia of the muscle, with fibers undergoing degeneration and subsequent regeneration. Scattered fibers around the periphery of the muscle survive this period of ischemia. The muscles were then allowed to regenerate for 30 days The number of muscle fibers in these grafts is essentially 
normal by this time (B. M. CARLSON. unpublished observations).

Group I (Standard reinnervated grafts). Five muscles were grafted as described above and were not subjected to further treatment at the time of surgery.

Group $I I$ (Bupivacaine-treated reinnervated grafts). Because some muscle fibers around the periphery of standard grafts survive the initial period of degeneration. all subsequent grafts were treated with $0.75 \%$ bupivacaine (Marcainc, Winthrop). Following removal from the limb, the 8 EDL muscles in this group were injected once with approx $0.5 \mathrm{ml}$ of bupivacaine and soaked in bupivacaine for $10 \mathrm{~min}$. The muscles were then replaced as detailed above.

Bupivacaine is a local anesthetic known to cause destruction of extrafusal muscle fibers (BENOIT \& BELT, 1970): Hall-CragGs, 1974). Combining bupivacaine treatment with free grafting eliminates virtually all surviving fibers and ensures a pure population of regenerating cells (CARL. SON, 1976). A degenerative effect of bupivacaine on intrafusal fibers in both intact and grafted muscles has been observed by MILBURN (1976) and HaNSEN-SMITH (personal communication).

Group III (Bupivacaine-treated, non-reinnervated grafis), Of the 8 muscles analyzed in this group, 6 were contralateral to those of group II. Grafting and bupivacaine treatment were performed as in group $\mathrm{II}_{;}$in addition, the entire limb was denervated by severing and ligating the sciatic nerve. Examination of silver-stained sections of sciatic nerves from these animals did not reveal any evidence of axonal regeneration. The low weights of the grafts in this group, when compared with those of groups I and II, is also indicative of denervation (Table 1).

Thirty days after surgery, grafted muscles from all experimental animals were removed, weighed and processed for light-microscopy. At this time, the experimental animals weighed between 350 and $\mathbf{4 0 0}$ grams. Additional bupivacaine-treated grafts were examined in order to determine that all intrafusal muscle fibers undergo degeneration following this treatment. These muscles were removed between 1 and 5 days after surgery and processed for lightmicroscopy.

\section{Histological processing}

Following fixation in Bouin's fluid. control and experi- mental muscles were dehydrated, embedded in paraffin. and serially cross-sectioned at $15 \mu \mathrm{m}$ t: few sections from each muscle were cut at $7 \mu \mathrm{m}$ for photographic purposes All sections were mounted and staned with Ehrlich s hematoxylin and eosin. In order wo determine the number of spindles per muscle, sections were examined at approx $100 \mu \mathrm{m}$ intervals, progressing from prosimal to distal ends of the muscle, and the appearance of each spindle was recorded. The primary criterion used to identify muselo spindles was the presence of a capsuk surrounding a vart able number of muscle fibers.

In order to determine that the muscles in group 11 were not innervated an the time of fixation. sections of the sciatio nerve. distal to the level of the original cut, were silver stained. A modification of the Palmgren silver impregna tion technique was followed (Hsu, 1974).

\section{RESUL TS}

Both intrafusal and extrafusal fibers in bupivacainetreated grafts undergo degeneration and phagocytosis (Fig. 1). Sections of these muscles examined 4 and 5 days after surgery did not reveal any healthy, surviving spindles, but spindle capsules could be identifed.

The mean number of spindles per muscle for each group is presented in Table 1. For non-operated control muscles, a mean of $37.86 \pm 3.02$ (S.D.) was found. This value agrees with a mean of $32.30 \pm 2.32$ (S.D.) reported by ZELENÁ \& HNIK (1960). Structures identifiable as spindles were observed in both reinnervated and non-reinnervated muscle grafts (Fig. 2). It is recognized that a strict definition of 'muscle spindle', in terms of ultrastructural and functional character. istics, cannot necessarily be applied to these structures. This is particularly true of those present in nonreinnervated grafts. The term is, however, retained for the sake of convenience. The standard reinnervated grafts (group I) contained $27.40 \pm 219$ (s.D.) spindles: muscle. Means for groups 11 lbupivacaine-treated reinnervated grafts) and III (bupivacaine-treated nonreinnervated grafts) were computed for all 8 muscles in each group. These means were $15.63 \pm 3.89$ (s.D.)

TABLE 1. MUSCLE WEIGHTS AND NUMBERS OK MUSCLE SPINDLES IN REINNER VATED ARU NON-REINNERVATED GRAFTS OF THE RAT EDL

\begin{tabular}{|c|c|c|}
\hline & $\begin{array}{l}\text { No. of spindles/muscle } \\
\text { (mean } \pm \text { S.D. }\end{array}$ & $\begin{array}{l}\text { Muscle weight } \\
\text { (mean } \pm \text { S.D.) }\end{array}$ \\
\hline $\begin{array}{l}\text { Control muscles } \\
(\mathbb{N}=7)\end{array}$ & $37.86 \pm 3.02$ & $205,67+31.40$ \\
\hline $\begin{array}{l}\text { Group } 1 \\
\text { Standard reinnervated } \\
\text { grafts } \\
(N=5)\end{array}$ & $27.40 \pm 2.19$ & $110.00 \pm 15.30$ \\
\hline $\begin{array}{l}\text { Group II } \\
\text { Bupivacaine-treated } \\
\text { reinnervated grafts } \\
(N=8)\end{array}$ & $15.63 \pm 3.89$ & $103.88 \pm 33.10$ \\
\hline $\begin{array}{l}\text { Group III } \\
\text { Bupivacaine-treated } \\
\text { non-reinnervated grafts } \\
(N=8)\end{array}$ & $18.38 \pm 5.15$ & $50.00 \pm 7.56$ \\
\hline
\end{tabular}




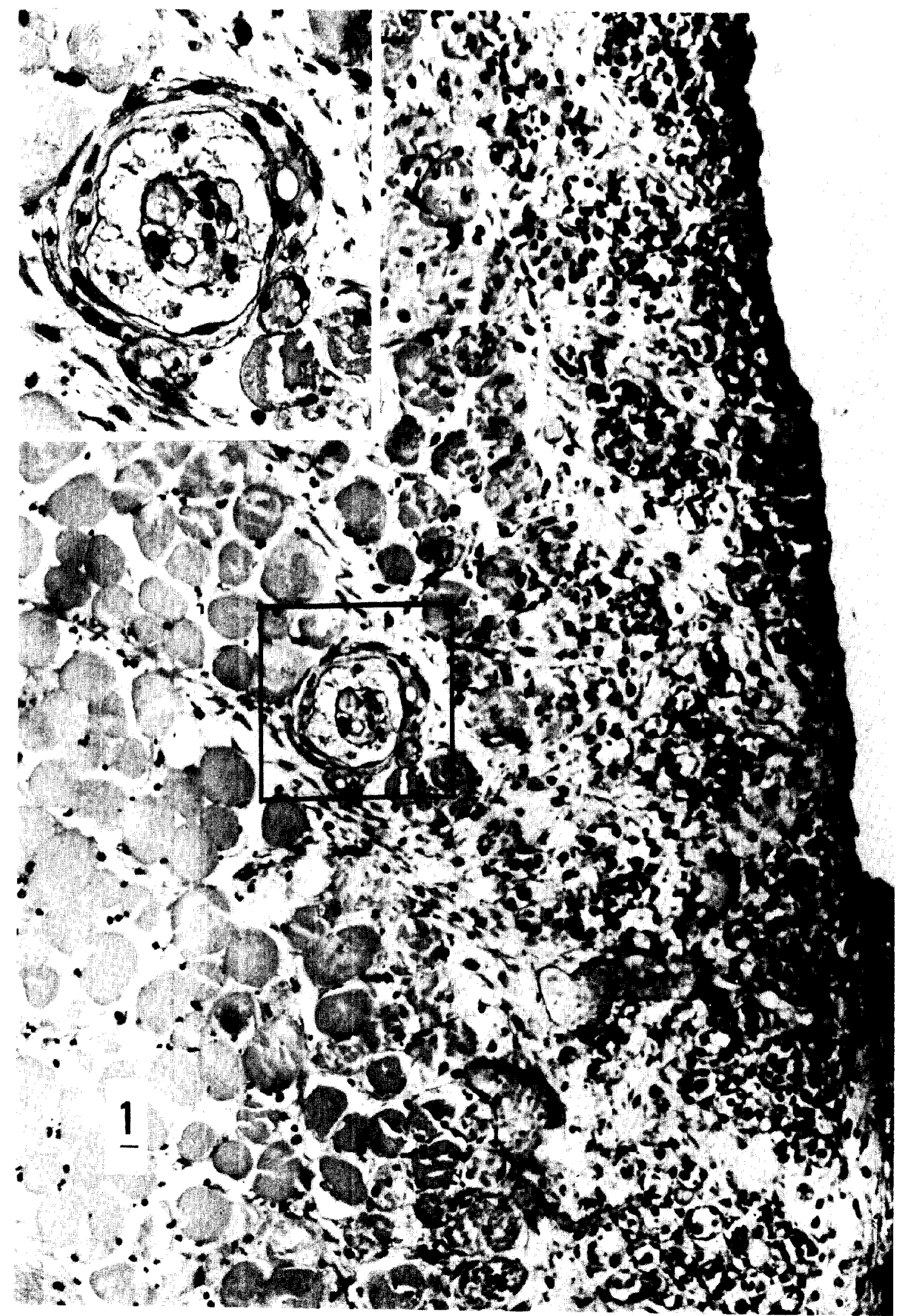

Flg. 1. Cross-section through a 3-day bupivacaine-treated graft. There is extensive degeneration of the extrafusal muscle fibers: those at the periphery of the graft have been phagocytized. The intrafusal fibers of a muscle spindte (inset) are fragmented and have been invaded by phagocytic cells. Note that the spindle capsule remains intact. $\times 290$. 


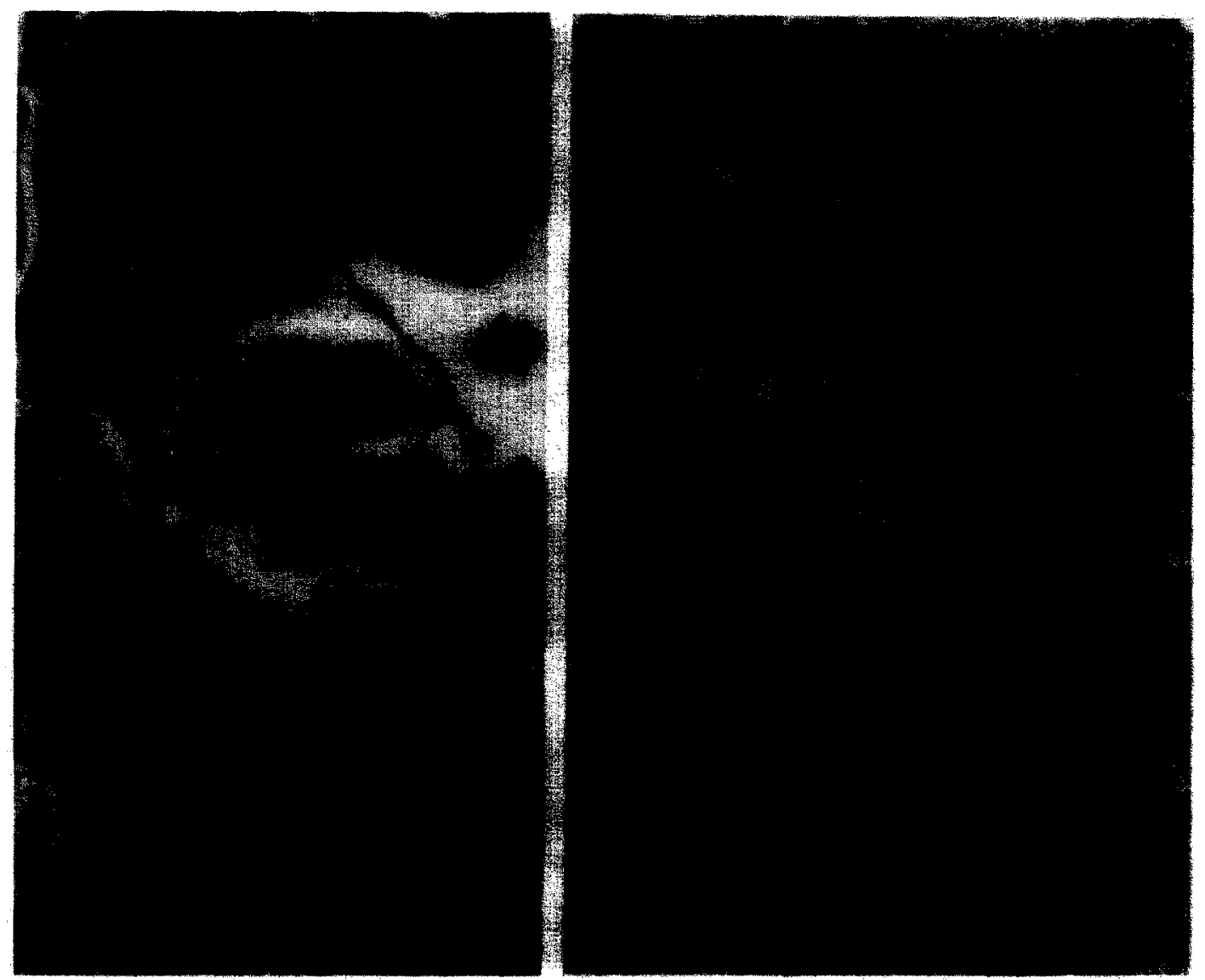

FIG. 2. Muscle spindles (single arrows) in cross-sections of 30-day bupivacaine-treated EDL grafts in the rat. Hematoxylin and eosin. $\times 570$. (a) Reinnervated graft. $A$ nerve $(N)$ lies adjacent to the spindle capsule. (b) Non-reinnervated graft. Note the small size of the muscle fibers and the large amount of connective tissue. The identification of the connective tissue remnants of a nerve (NR) was confirmed by examination of adjacent sections. Silver staining of sections of the sciatic nerve, distal to the point of denervation. has established that axons have not regenerated into the limb. A small blood vessel (double arrows) is also present. 


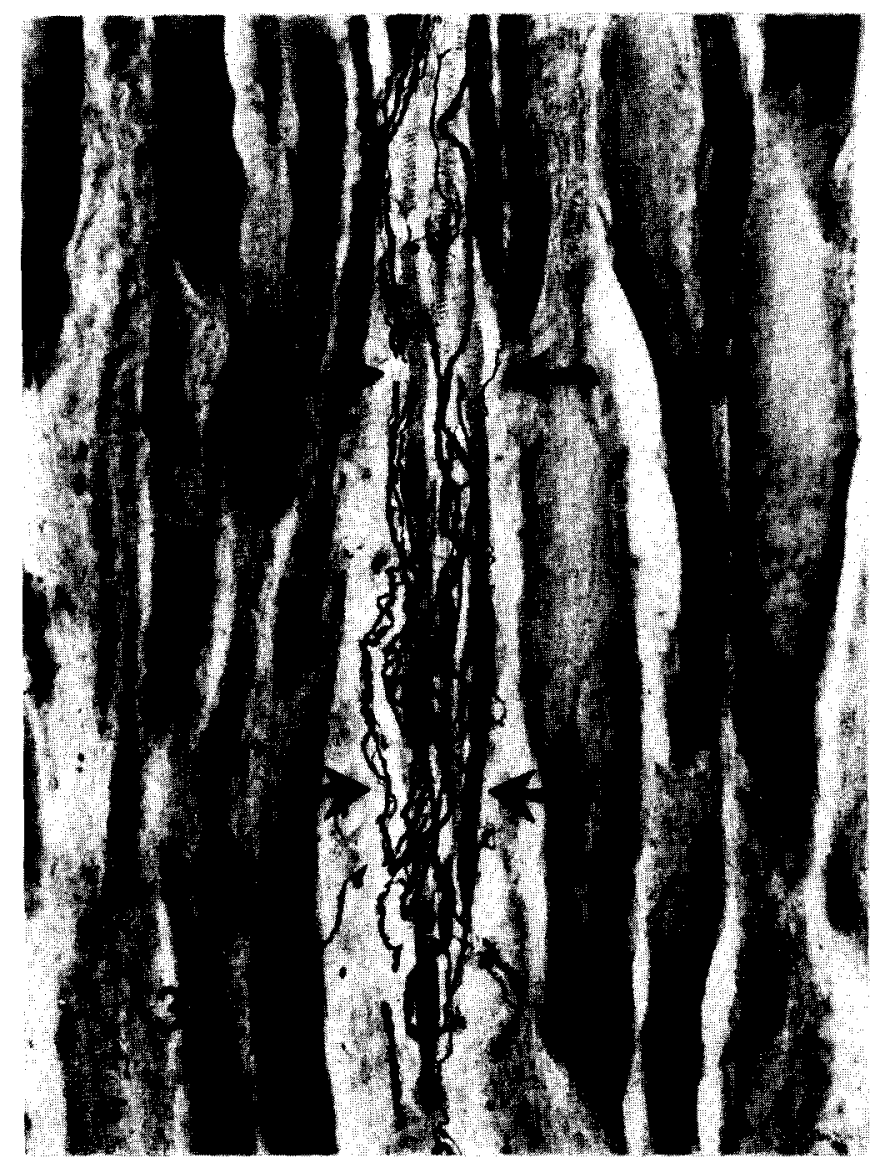

FIG. 3. Longitudinal section of a muscle spindle (between arrows) in a 30-day reinnervated graft of the rat EDL muscle. Note the large number of nerve fibers surrounding the intrafusal muscle fibers. Combined silver and acetylcholinesterase stain. $\times 260$. 
and $18.38 \pm 5.15$ (S.D.) spindles respectively. Statistical analysis of mean values for the contralateral muscles in groups II and III was performed using a paired t-test. No significant difference between these groups could be found (attained significance level $=0.4296$ ) All experimental values, however, were lower than the control mean, those of groups II and III being approximately one-half of this value.

\section{DISCUSSION}

This study demonstrates that muscle spindles form in substantial numbers in both reinnervated and nonreinnervated grafts of the rat EDL muscle. The fact that spindle regeneration in these muscles can occur in the absence of nerves is in contrast to their embryonic development. In rats, muscle spindles in lower hindlimb muscles begin to form during the late fetal period when sensory nerve fibers contact developing myotubes. SCHIAfFino \& Pierobon Bormiol (1976). Werner (1973), ZeLENÁ (1957) and ZFLENÁ \& Soukup (1973) have shown that this initial afferent innervation is critical to differentiation of intrafusal fibers in terms of both their morphological and histochemical characteristics. In view of the contrast between spindle regeneration and embryogenesis, what factors might be involved in their formation in regenerating muscle grafts?

MLiburn (1976) has studied the degeneration and regeneration of intrafusal fibers at the ultrastructural level in bupivacaine-injected, non-transplanted, rat peroneus longus muscles. In her study, the spindle capsule remained intact and satellite cells, similar to those involved in the regeneration of extrafusal fibers (SNow. 1978). survived within it. These myoblastic cells seem to participate in the formation of new intrafusal fibers. Milburn's experimental system differs from that used in the present study because neuromuscular and vascular connections were not disrupted and complete fiber degeneration could not be ensured. However, observations similar to Milburn's have been noted by SCHMALBRUCH (1976) in grafted soleus muscles of the rat and by F. M. HANSEN-SMITH (personal communication) in grafts of the rat EDL muscle.

The apparent role of the capsule and of satellite cells in muscle spindle regeneration might help to explain the low number of spindles in all experimental groups in the present study. Satellite cell death is possible in regenerating grafted muscle, where cells in the center of the graft remain in a state of prolonged ischemia (CARlson, HaNsen-SMith \& Magon, 1979). The importance of the capsule in providing a framework for intrafusal fiber regeneration is suggested by the absence of spindles in minced muscle regenerates (CARLSON, 1973; Zelená \& SobotKova, 1971; ZheNEVSKAYA, 1974) where it is likely that the mincing procedure disrupts these capsules to a considerable degree. In our study, intact capsules can be identified during all stages of intrafusal fiber degeneration and regeneration. Since there is not a distinct pattern of distribution of spindles in the rat EDL (YELLIN, 1969), it is difficult to compare their location in grafts and control muscles. However, we did not observe a consistent lack of spindles in any particular area of the grafts.

For this quantitative study, muscle spindles were identified as any group of encapsulated muscle fibers. No judgement was made as to whether or not these fibers resemble normal intrafusal fibers in terms of detailed morphological and histochemical characteristics. As discussed above, intrafusal fiber differentiation during development is dependent upon properly timed sensory innervation. The work of MILBURN (1976) suggests that this is also true of muscle spindle regeneration. When reinnervation of regenerating muscle grafts is allowed (groups $I$ and II in this study), nerves do not enter the graft until 7-10 days after surgery (CARLSON, WAGNER \& MAX, 1979), when the majority of myotubes have begun to mature. Although some immature myotubes have been observed at this stage (F. M. HANSEN-SMITH, personal communication), it is not known whether these, or the more mature muscle fibers are capable of response to sensory innervation. We have observed that, in reinnervated grafts, muscle spindles are often surrounded by a large number of nerve fibers (Fig. 3). In addition to having implications for intrafusal fiber differentiation, proper reinnervation would be crucial to the functional capabilities of these spindles. Studies in progress should elucidate aspects of these questions.

Acknowledgements -We are grateful to Mr J. BECKERMAN for assistance with the photography and to Mr K. GUIRE of the Statistical Research Laboratory, University of Michigan, for the statistical analysis.

This research was supported by grants from the Muscular Dystrophy Association and National Institutes of Health (NS 13116).

\section{REFERENCES}

BENom P. W. \& BELT D. (1970) Destruction and regeneration of skeletal muscle after treatment with a local anesthetic, bupivacaine (Marcaine). J. Anat. 107, 547.-556.

CARLSON B. M. (1973) The regeneration of skeletal muscle-a review. Am. J. Anat. 137, 119-150.

CARLSON B. M. (1976) A quantitative study of muscle fiber survival and regeneration in normal, predenervated, and Marcaine-treated free muscle grafts in the rat. Expl Neurol. 52, 421 432.

CARLSON B. M. \& GUTMANN E. (1975) Regeneration in free grafts of normal and denervated muscles in the rat: morphology and histochemistry. Anat. Rec. 183, 47-62

CARISON B. M., HANSEN-SMTth F. M. \& MAGON D. K. (1979) The life history of a free muscle graft. In Muscle Reqeneration (ed. MaURO A.) pp. 493-507. Raven Press. New York. 
Carlson B. M., Wagner K. R. \& Max S. R. (1979) Reinnervation of rat extensor digitorum longus musctes after freq? grafting. Muscle and Nerve, 2, 304-307.

Hakeluus L., Nyström B. \& Stålberg E. (1975) Histochemical and neurophysiological studies of athutransplanted cat muscle. Scand. J. Plast. Reconstr. Surg. 9, 15 24.

Hall-Craggs E. C. B. (1974) Rapid degeneration and regeneration of a whole skeletal muscle following treatment with bupivacaine (Marcaine). Expl Netrol. 43, 349-358.

Hsu L. (1974) The role of nerves in the regeneration of minced skeletal muscle in adult anurans. Anat. Ket.179,119 136.

MLburn A. (1973) The early development of muscle spindles in the rat. J. Cell Sci. 12, 175195.

Milburn A. (1976) The effect of the local anesthetic bupivacaine on the muscle spindle of rat. J. Netmolytol. 5, 425-446.

Schiaffino S. \& Pierobon Bormioli S. (1976) Morphogenesis of rat muscle spindles after nerve lesion during early postnatal development. J. Neurocytol. 5, 319 -336.

SCHMALBRUCH H. (1976) Regeneration of soleus muscles of rat autografted in toto as studied by electron microscopy. (C)ll Tissue Res. 177, 159 180

SNow M. H. (1978) An autoradiographic study of satellite cell differentiation into regenerating myotubes following transplantation of muscle in young rats. Cell Tissue Res, 186, $535-540$.

WERNER J. K. (1973) Duration of normal innervation required for complete differentiation of muscle spindles in newborn rats. Expl Neurol. 41, 214-217.

YeLLIN H. (1969) A histochemical study of muscle spindles and their relationship to extrafusal fiber types in the rat, Am. 3 . Anat. 125, 3146.

ZELEN J J. (1957) The morphogenetic influence of innervation on the ontogenetic development of muscle-spindles. $J$. Embryol exp. Morph. 5, 283-292.

ZelenÁ J. \& Hníx P. (1960) Absence of spindles in muscles of rats reinnervated during development. Physiot. Bohemosiov. 9, 373-381.

Zelená J. \& Sobotrova M. (1971) Absence of muscle spindles in regenerated muscles of the rat. Physinlogia bohemostot. 20, 433-439.

ZELENÁ J. \& Soukup T. (1973) Development of muscle spindles deprived of fusimotor innervation. Z., Zellforsch mikrosk. Anat. 144, 435-452.

ZhenevsKaya R. P. (1974) Neurotrophic Regulation of Plastic Acticity in Muscle Tissue (in Russian). 240 pp. Nauka, Moscow. 